\title{
Analysis of QTLs for panicle exsertion and its relationship with yield and yield-related traits in rice (Oryza sativa L.)
}

\author{
C.F. Zhao*, T. Chen*, Q.Y. Zhao, L.H. Zhou, L. Zhao, Y.D. Zhang, \\ Z. Zhu, S. Yao and C.L. Wang \\ Institute of Food Crops, \\ Jiangsu High Quality Rice Research and Development Center, \\ Nanjing Branch of China National Center for Rice Improvement, \\ Jiangsu Academy of Agricultural Sciences, Nanjing, China \\ *These authors contributed equally to this study. \\ Corresponding author: C.L. Wang \\ E-mail: clwang@jaas.ac.cn
}

Genet. Mol. Res. 15 (2): gmr.15027423

Received October 13, 2015

Accepted December 28, 2015

Published April 27, 2016

DOI http://dx.doi.org/10.4238/gmr.15027423

\begin{abstract}
Panicle exsertion (PE) is an important morphological trait that is closely associated with spikelet fertility and grain yield. To understand the genetic basis of PE and its relationships with yield and yield-related traits, a recombinant inbred population consisting of 240 lines derived from a cross between an Indica cultivar 'Kasalath' and a Japonica germplasm 'TD70', was studied over two years. PE was significantly correlated with plant height, heading date (HD), panicle length (PL), and panicle characteristics such as primary branch number, spikelet number per panicle, and spikelet density, but showed poor correlation with yield components. Based on linkage mapping of 141 SSR markers, a total of 38 quantitative trait loci (QTLs) were located for 12 investigated traits, with the contribution varying from 6.51 to $8.61 \%$. Among these, four QTL clusters were identified on chromosomes 1, 2,3 , and 6 , suggesting the existence of pleiotropic alleles. In some
\end{abstract}


intervals, two loci for PE were collocated with several traits, which is consistent with the correlations observed with phenotypic variations. The PE QTLs with 'Kasalath' alleles and without pleiotropic effects would be valuable for the improvement of PE in 'TD70' and in other rice varieties.

Key words: Oryza sativa L.; QTL; Panicle exsertion; Recombinant inbred population; Yield-related traits

\section{INTRODUCTION}

In rice, stem development involves internode elongation in the vegetative phase and the expansion of panicle elements in the reproductive phase (Kende et al., 1998). The panicle neck, which connects the culm and the panicle, reflects the conversion from vegetative growth to a reproductive stage. It plays an important role in high yield and better grain filling in rice through the efficient transport of water and nutrients from the leaves and stems (Cui et al., 2003). The diameter of the panicle neck is strongly correlated with the total sink capacity and grain weight, which are affected by the conductive tissue together with the source strength (Sasahara et al., 1999; Liu et al., 2008). Panicle neck length, known as 'panicle exsertion' (PE), is also considered to be essential for enhancing total sink capacity and grain filling by improving the transport efficiency of assimilates (Ma et al., 2002; da Cruz et al., 2008). Incomplete PE (also named sheathed panicle) is an adverse symptom observed in rice plants, which is associated with almost all cytoplasmic male sterile lines during the production of hybrid rice seeds (Shen et al., 1987). Sheathed panicles are usually found in rice germplasm or cultivar and can reduce grain yield and increase the incidence of disease (da Cruz et al., 2008). To improve PE of rice germplasms or varieties, it is necessary to understand its genetic control.

To date, numerous PE mutants have been identified, and their controlling genes have been characterized in rice. Mutants with enhanced PEs often show increased plant height (PH), while the shrunken mutants have a dwarf phenotype. Several genetic studies have revealed that the culm elongation or decrement mutations derive from excess or deficient biosynthesis of plant hormones such as gibberellins (GAs) and brassinosteroids (BRs), respectively. For example, elongated uppermost internode (eui) mutants exhibit an elongated $\mathrm{PE}$ and $\mathrm{PH}$ as a result of elevated GA levels (Yang et al., 2001; Luo et al., 2006). Conversely, several dwarf rice mutants show defective BR biosynthesis and signaling (Je et al., 2010). Recently, enzymes associated with tissue development were reported to regulate the elongation of PE. The shortened uppermost internode 1 (suil) mutant was characterized as having symptoms of a sheathed panicle, and the gene responsible was found to encode a putative phosphatidyl serine synthase (Zhu et al., 2011). Three SUI family genes (SUI1, SUI2, and SUI3) in rice, which encode base-exchange-types of phosphatidyl serine synthases, were shown to regulate the development of the intercalary meristem for culm or internode elongation (Yin et al., 2013). These studies on mutant plants reveal that multiple genes are involved in the regulation of PE.

Quantitative trait locus (QTL) analysis is based on genetic linkage maps and is a powerful tool that can be used to investigate the genetic basis of complicated agronomic traits. Recently, studies of QTL mapping for panicle- and yield-related traits have been performed in rice (Liu et al., 2012; Bian et al., 2013; Cai et al., 2015), allowing several important agronomic genes such as $q S H 1, P L O G 1$, and $q S W 5$ to be cloned and functionally analyzed (Konishi et al., 
2006; Weng et al., 2008; Wang and Li, 2011), which are of great significance for rice breeding and genomics. PE is a typically and quantitatively inherited trait in mapping populations derived from different rice varieties with natural allelic variation (Yamamoto et al., 2001; Qiao et al., 2008). Based on data in the QTL Annotation Rice Online database (http://qtaro.abr. affrc.go.jp/), dozens of QTLs for PE have been documented on rice chromosomes 1, 2, 3, 4, 6, $8,9,11$, and 12 , providing important information for studying the genetic basis and breeding application of panicle exsertion.

A set of recombinant inbred lines (RILs) was developed from a cross between an Indica variety 'Kasalath' and a Japonica germplasm 'TD70' with extra-large grain size (Dong et al., 2012). 'TD70' has a large grain size and grain weight, strong lodging resistance, good grain quality, and a temperate plant type. It has suitable $\mathrm{PH}$, flag leaf length, and tiller angle, but a short PE, with sheathed panicles observed among various planting seasons or conditions, and lower grain filling. QTL analyses have been conducted for grain size and grain weight traits in the RILs (Zhang et al., 2013). However, many other primary target traits for breeding selection, such as PE, panicle components, and yield traits, have not been genetically identified in the population.

In this study, PE, yield, and yield-related traits were investigated in the RIL population in 2012 and 2013. Phenotypic correlations between PE and other agronomic traits and QTLs for these traits were evaluated individually. QTLs and QTL clusters for PE are discussed in detail. This study aimed to uncover valuable QTLs that influence PE, which can be used to improve PE of 'TD70' and other rice varieties.

\section{MATERIAL AND METHODS}

\section{Plant materials}

The RIL population consisted of 240 lines and was developed by crossing an Indica variety 'Kasalath' and a Japonica germplasm 'TD70', which has a large grain phenotype. The $240 \mathrm{~F}_{9}$ and $\mathrm{F}_{10}$ generation lines, together with the parent lines, were planted during the rice growing season of 2012 and 2013 in the experimental field of Jiangsu Academy of Agricultural Sciences, Nanjing, China $\left(32.04^{\circ} \mathrm{N}, 118.87^{\circ} \mathrm{E}\right)$. Seeds of all lines were sown on May 10, and seedlings were transplanted into the paddy field on June 10. Each line was planted into a plot containing four rows with ten plants per row, arranged in a completely randomized design with two replicates. The parental materials were planted in triplicate. The plant spacing was $26.7 \mathrm{~cm}$ (row space) x $16.7 \mathrm{~cm}$ (plot space). Field management followed the normal agricultural practices for applied fertilizer (per hectare) as follows: $50 \mathrm{~kg} \mathrm{~N}, 60 \mathrm{~kg} \mathrm{P}$, and $95 \mathrm{~kg} \mathrm{~K}$ as basic fertilizer; $90 \mathrm{~kg} \mathrm{~N}$ at the largest tilling stage; and $30 \mathrm{~kg} \mathrm{~N}$ at the heading stage.

\section{Trait measurements}

Five plants per line were randomly selected from the middle two rows of each plot and investigated for PE (in $\mathrm{cm}$ ) and for other agronomical traits. PE was measured from the flag leaf to the panicle base in each tiller using a ruler. When the flag leaf overlapped the panicle base, the value of PE was marked as 0 ; when the panicle base was under the flag leaf, 
a negative value was assigned. The degree of panicle enclosure (also named sheathed panicle) was reflected by a negative $\mathrm{PE}$ value.

$\mathrm{PH}$ (in $\mathrm{cm}$ ), PE (in $\mathrm{cm}$ ), PL (in $\mathrm{cm}$ ), and panicle number (PN) were measured in the field. The primary branch number (PBN), spikelet number per panicle (SNP), grain number per panicle (GNP), 1000-grain weight (TGW, in $\mathrm{g}$ ), and grain weight per plant (GW, in $\mathrm{g}$ ) were measured after harvest. The length traits were measured using a ruler or a meter rule (measured to the nearest $0.01 \mathrm{~cm}$ ), while the weight traits were measured using an electronic balance (measured to the nearest $0.0001 \mathrm{~g}$ ). Spikelet density (SD $=$ SNP/PL) and spikelet fertility $(\mathrm{SF}=\mathrm{GNP} / \mathrm{SNP})$ were calculated from the corresponding traits. The average value from two replicates per year was used for QTL analysis.

\section{Statistical analysis and QTL mapping}

Combined analysis of variance (ANOVA) using data obtained each year from three replicates of the parental materials was performed to estimate the variance components as described by Bian et al. (2013). Correlation analysis was performed to detect association between different traits based on the average value of each line using the SPSS software.

To explore the gene expression for PE and other yield-related traits in the RIL population in difference years, QTL analysis was performed using composite interval mapping with the QTL IciMapping version 3.1 computer program (Li et al., 2007). A threshold of LOD score 2.5 was adopted to confirm the existence of a locus. The threshold was estimated by 1000 permutations at a significance level of $\mathrm{P}=0.001$ (Churchill and Doerge, 1994). Before QTL analysis was performed, a molecular linkage map was constructed using Mapmaker 3.0 (Lincoln et al., 1992), which spanned $1832.47 \mathrm{cM}$ of the rice genome with an average distance of $12.7 \mathrm{cM}$ between adjacent markers (Dong et al., 2012). The linkage map consisted of 141 microsatellite markers [single nucleotide repeats (SSRs)] derived from the Cornell SSR linkage map (McCouch et al., 2002). QTL nomenclature followed that of McCouch et al. (1997).

\section{RESULTS}

\section{Performance of PE and yield-related traits}

PE and 11 other yield-related traits in parents and in the RIL population were evaluated in 2012 and 2013. Their phenotypic differences are summarized in Table 1. ANOVA revealed no significant difference $(\mathrm{P}>0.05)$ among the agronomic traits in the two parents, indicating minimal environmental impact on this planting region. Relative to 'Kasalath', 'TD70' showed significantly shorter PE at the 1\% probability level in both years, as well as shorter PH, fewer PBN, PN, SNP, and GNP, smaller SD, with higher TGW and GW, which were attributed to its larger grain size. There were no significant differences between parents for HD and PL. Among the RIL population, all the agronomic traits exhibited wide variations and transgressive segregants except for SF and TGW (Table 1 and $\underline{\text { S1 Figure) }}$. Diverse phenotypes for PE and panicle characteristics in parents and parts of the RILs are presented in Figure 1. All the traits showed continuous and normal distribution in this RIL population ( $\underline{\text { S1 Figure }})$. 
Table 1. Statistical analysis of panicle exsertion and yield-related traits in parent plants and in the RIL population in 2012 (upper values) and 2013 (lower values).

\begin{tabular}{|c|c|c|c|c|}
\hline \multirow[t]{2}{*}{ Trait name } & \multicolumn{2}{|c|}{ Parents (mean $\pm \mathrm{SD}$ ) } & \multicolumn{2}{|c|}{ RIL population } \\
\hline & 'Kasalath' & 'TD70' & Means \pm SD & Range \\
\hline Panicle exsertion (PE, cm) & $\begin{array}{l}8.57 \pm 1.47^{* *} \\
6.42 \pm 2.09^{* *}\end{array}$ & $\begin{array}{l}2.80 \pm 1.56 \\
1.97 \pm 1.65\end{array}$ & $\begin{array}{l}5.57 \pm 4.06 \\
6.15 \pm 4.62\end{array}$ & $\begin{array}{l}-5.98-16.53 \\
-4.97-19.51 \\
\end{array}$ \\
\hline Heading date (HD, days) & $\begin{array}{l}91.30 \pm 1.15 \\
90.00 \pm 0.00\end{array}$ & $\begin{array}{l}93.00 \pm 0.00 \\
92.50 \pm 1.13\end{array}$ & $\begin{array}{l}100.09 \pm 7.80 \\
101.01 \pm 7.35\end{array}$ & $\begin{array}{l}77.00-125.00 \\
77.00-122.00\end{array}$ \\
\hline Plant height $(\mathrm{PH}, \mathrm{cm})$ & $\begin{array}{l}162.73 \pm 1.31^{* *} \\
173.14 \pm 3.49^{* *}\end{array}$ & $\begin{array}{l}107.32 \pm 3.57 \\
122.45 \pm 2.48\end{array}$ & $\begin{array}{l}145.75 \pm 19.67 \\
154.03 \pm 21.52\end{array}$ & $\begin{array}{l}95.16-214.72 \\
90.60-219.60\end{array}$ \\
\hline Panicle length (PL, cm) & $\begin{array}{l}29.20 \pm 1.76 \\
30.25 \pm 2.45\end{array}$ & $\begin{array}{l}28.59 \pm 2.64 \\
28.98 \pm 1.32\end{array}$ & $\begin{array}{l}29.05 \pm 4.27 \\
31.47 \pm 4.99\end{array}$ & $\begin{array}{l}16.89-40.84 \\
17.30-46.10\end{array}$ \\
\hline Primary branch number $(\mathrm{PBN})$ & $\begin{array}{l}10.00 \pm 1.67 * * \\
11.15 \pm 1.54 * *\end{array}$ & $\begin{array}{l}7.35 \pm 1.07 \\
7.59 \pm 1.23\end{array}$ & $\begin{array}{c}9.66 \pm 1.92 \\
11.12 \pm 1.53\end{array}$ & $\begin{array}{l}6.14-16.00 \\
7.23-18.23\end{array}$ \\
\hline Spikelet number per panicle (SNP) & $\begin{array}{l}182.82 \pm 54.28^{* *} \\
186.12 \pm 56.45^{* *}\end{array}$ & $\begin{array}{c}44.38 \pm 9.41 \\
52.02 \pm 10.02\end{array}$ & $\begin{array}{l}118.68 \pm 40.38 \\
117.26 \pm 44.86\end{array}$ & $\begin{array}{l}45.67-236.70 \\
49.54-216.13\end{array}$ \\
\hline Grain number per panicle (GNP) & $\begin{array}{l}164.33 \pm 47.99^{* *} \\
166.45 \pm 32.89^{* *}\end{array}$ & $\begin{array}{l}35.17 \pm 6.52 \\
43.09 \pm 10.5\end{array}$ & $\begin{array}{l}73.75 \pm 27.62 \\
86.87 \pm 30.60\end{array}$ & $\begin{array}{r}12.48-172.29 \\
17.64-183.72\end{array}$ \\
\hline Spikelet density (SD) & $\begin{array}{l}6.70 \pm 1.31^{* *} \\
6.35 \pm 2.01^{* *}\end{array}$ & $\begin{array}{l}1.52 \pm 0.25 \\
1.86 \pm 1.56\end{array}$ & $\begin{array}{l}4.41 \pm 1.45 \\
3.86 \pm 1.45\end{array}$ & $\begin{array}{l}1.63-9.30 \\
1.34-9.22\end{array}$ \\
\hline Panicle number (PN) & $\begin{array}{l}19.50 \pm 1.50^{* *} \\
18.89 \pm 3.45^{* *}\end{array}$ & $\begin{array}{l}8.50 \pm 3.18 \\
7.56 \pm 3.95\end{array}$ & $\begin{array}{l}14.40 \pm 5.34 \\
15.55 \pm 6.25\end{array}$ & $\begin{array}{l}5.00-35.25 \\
4.40-35.86 \\
\end{array}$ \\
\hline Spikelet fertility (SF) & $\begin{array}{l}0.86 \pm 0.03 * \\
0.92 \pm 0.08 *\end{array}$ & $\begin{array}{l}0.73 \pm 0.07 \\
0.78 \pm 0.10\end{array}$ & $\begin{array}{l}0.62 \pm 0.10 \\
0.73 \pm 0.10\end{array}$ & $\begin{array}{l}0.20-0.80 \\
0.29-0.90\end{array}$ \\
\hline 1000-grain weight (TGW, g) & $\begin{array}{l}20.25 \pm 1.52 \\
21.03 \pm 1.47\end{array}$ & $\begin{array}{l}65.75 \pm 4.55^{* *} \\
68.41 \pm 3.22^{* *}\end{array}$ & $\begin{array}{l}34.59 \pm 8.40 \\
31.21 \pm 7.21\end{array}$ & $\begin{array}{l}18.80-63.83 \\
18.00-55.40\end{array}$ \\
\hline Grain weight per plant $(\mathrm{GW}, \mathrm{g})$ & $\begin{array}{l}49.17 \pm 8.23 \\
52.45 \pm 9.89\end{array}$ & $\begin{array}{l}72.76 \pm 7.45^{* *} \\
74.52 \pm 5.89^{* *}\end{array}$ & $\begin{array}{l}38.34 \pm 16.53 \\
35.12 \pm 15.02\end{array}$ & $\begin{array}{c}1.76-103.04 \\
1.72-99.65\end{array}$ \\
\hline
\end{tabular}

$*, * *$ Represent significance at 0.05 and 0.01 levels, respectively, based on the $t$-test; RIL $=$ recombinant inbred line.

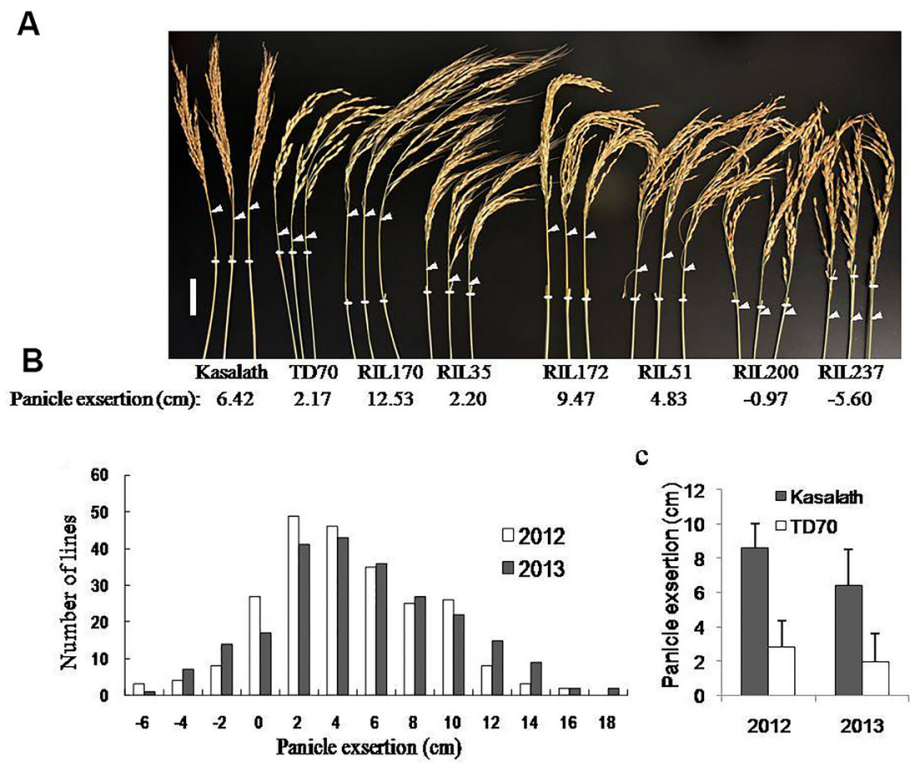

Figure 1. Performance of panicle exsertion in parent plants and in the recombinant inbred line (RIL) population. A. Panicle exsertion phenotypes and panicle characteristics in parents and parts of RILs. Short white lines indicate the position of the flag leaf base and arrowheads indicate the position of the panicle base; negative values reflect the degree of sheathed panicle. Bar $=4 \mathrm{~cm}$. B. Frequency distribution of panicle exsertion in the RIL population. C. Panicle exsertion of two parent plants in 2012 and 2013. 


\section{Correlation between PE and yield-related characters}

The coefficients of pairwise correlations between PE and yield-related traits are shown in Table 2. PE was highly intercorrelated between both years, implying that it was largely determined by genotype. PE was correlated with nine yield-related traits at the 5\% level of significance in at least one year. Positive correlations with PE were found for PH, PL, and TGW, and negative correlations were found for panicle characteristics such as primary PBN, SNP, GNP, and SD in both years. This indicated that RILs with longer PEs usually had longer culms and panicles and smaller numbers of primary branches and spikelets. PE was also negatively correlated with $\mathrm{HD}$ and GW in one year, but showed relatively low correlations with PN and SF.

Table 2. Correlation of panicle exsertion (PE) with other agronomic traits in the RILs and the number of QTLs for each trait located near PE QTLs.

\begin{tabular}{|c|c|c|c|c|}
\hline \multirow[t]{2}{*}{ Trait name } & \multicolumn{2}{|c|}{2012} & \multicolumn{2}{|c|}{2013} \\
\hline & Correlation with PE & No. of QTLs ${ }^{b}$ & Correlation with PE & No. of QTLs ${ }^{b}$ \\
\hline $\mathrm{PE}$ & \multicolumn{4}{|c|}{$0.805^{* * a}$} \\
\hline HD & $-0.128 *$ & $2(0)$ & -0.080 & $4(1)$ \\
\hline $\mathrm{PH}$ & $0.332 * *$ & $1(1)$ & $0.347 * *$ & $3(2)$ \\
\hline PL & $0.202 * *$ & $3(1)$ & $0.131^{*}$ & $0(0)$ \\
\hline PBN & $-0.191 * *$ & $2(1)$ & $-0.256^{* *}$ & $1(1)$ \\
\hline SNP & $-0.207^{* *} *$ & $1(0)$ & $-0.173 * *$ & $1(0)$ \\
\hline GNP & $-0.139 * *$ & $2(0)$ & $-0.223 * *$ & $2(0)$ \\
\hline SD & $-0.250 * *$ & $6(1)$ & $-0.270 * *$ & $6(2)$ \\
\hline $\mathrm{PN}$ & -0.063 & $2(1)$ & -0.105 & $0(0)$ \\
\hline$\overline{S F}$ & 0.071 & $1(0)$ & 0.079 & $2(0)$ \\
\hline TGW & 0.109 & $2(0)$ & $0.138^{*}$ & $4(0)$ \\
\hline $\mathrm{GW}$ & $-0.138^{*}$ & $0(0)$ & $-0.166^{* *}$ & $0(0)$ \\
\hline
\end{tabular}

$\mathrm{HD}=$ heading date; $\mathrm{PH}=$ plant height $\mathrm{PL}=$ panicle length; $\mathrm{PBN}=$ primary branch number; $\mathrm{SNP}=$ spikelet number per panicle; $\mathrm{GNP}=$ grain number per panicle; $\mathrm{SD}=$ spikelet density; $\mathrm{PN}=$ panicle number; $\mathrm{SF}=$ spikelet fertility; TGW $=1000$-grain weight; $\mathrm{GW}=$ grain weight per plant. ${ }^{* * *}$ Significance at the 0.05 and 0.01 levels, respectively, based on the $t$-test. ${ }^{a}$ Correlation coefficient between the PE traits investigated in 2012 and 2013. ${ }^{\mathrm{b}}$ Figures in parentheses indicate the number of QTLs located near QTLs of PE.

\section{QTL identification}

Using a linkage map consisting of 141 SSR markers, a total of 38 QTLs were detected for 12 agronomic traits that were measured in 2012 and 2013 (Table 3). The QTLs were distributed on all rice chromosomes except for chromosomes 5 and 10 (Figure 2). Five QTLs ( $q P E 1, q P E 3, q P E 6, q P E 9$, and $q P E 11)$ were identified for PE, each with a $6.51-8.61 \%$ contribution of phenotypic variation. $Q P E 1$ and $q P E 9$ were two common QTLs detected across the two years. Alleles that increased or decreased phenotypic variation of PE were found in 'Kasalath' and 'TD70', respectively. Four QTL clusters that constituted more than four traits were observed on the long arms of chromosomes 1,3, and 6, and the short arm of chromosome 2 (Figure 2). QPE1 and qPE6 were located in two clusters on chromosome 1 and 6, respectively. QTLs for traits significantly correlated with PE tended to be located near QTLs of PE (Table 2), indicating that there was pleiotropism or tight linkage of the contributing alleles. QTLs with relatively large effects were co-located with 
the QTL clusters, which suggested that most of the agronomic traits were controlled by the major genes in these clusters.

\begin{tabular}{|c|c|c|c|c|c|c|c|c|c|}
\hline \multirow[t]{2}{*}{ Trait } & \multirow[t]{2}{*}{ QTL } & \multirow[t]{2}{*}{ Chr } & \multirow[t]{2}{*}{ Marker interval } & \multicolumn{3}{|c|}{2012} & \multicolumn{3}{|c|}{2013} \\
\hline & & & & LOD & $R^{2}(\%)$ & Add & LOD & $R^{2}(\%)$ & Add \\
\hline \multirow[t]{5}{*}{$\mathrm{PE}$} & $q P E 1$ & 1 & RM5389-RM165 & 2.93 & 7.87 & -1.23 & 2.6 & 7.56 & -1.62 \\
\hline & $q P E 3$ & 3 & RM1278-RM3766 & 2.79 & 8.61 & -1.24 & & & \\
\hline & qPE6 & 6 & RM6782-RM3343 & & & & 2.8 & 8.46 & -1.52 \\
\hline & qPE9 & 9 & RM553-RM215 & 3.34 & 7.30 & 1.14 & 2.5 & 6.51 & 1.44 \\
\hline & $q P E 11$ & 11 & RM5349-RM1233 & 3.82 & 7.16 & 1.11 & & & \\
\hline \multirow[t]{4}{*}{ HD } & $q H D 3$ & 3 & RM3564-RM85 & 6.12 & 12.87 & 3.25 & 3.12 & 7.70 & 1.59 \\
\hline & $q H D 6.1$ & 6 & RM510-RM253 & 5.21 & 10.99 & -2.44 & 2.97 & 5.58 & -1.86 \\
\hline & $q H D 6.2^{a}$ & 6 & RM3343-RM412 & & & & 2.97 & 4.77 & 2.05 \\
\hline & $q H D 7$ & 7 & RM1253-RM214 & 6.86 & 13.82 & -2.89 & 6.71 & 12.96 & -2.64 \\
\hline \multirow[t]{3}{*}{$\mathrm{PH}$} & $q P H 1^{a}$ & 1 & RM5389-RM165 & 10.75 & 32.43 & -11.60 & 11.06 & 34.41 & -13.04 \\
\hline & $q P H 6^{a}$ & 6 & RM3628-RM6782 & & & & 3.50 & 7.31 & -5.88 \\
\hline & $q P H 12$ & 12 & RM7119-RM277 & & & & 3.52 & 10.75 & -7.06 \\
\hline \multirow[t]{3}{*}{ PL } & $q P L 1^{a}$ & 1 & RM165-RM6407 & 4.21 & 11.97 & -1.49 & & & \\
\hline & $q P L 3$ & 3 & RM6080-RM6832 & 3.74 & 6.40 & 1.08 & & & \\
\hline & $q P L 9$ & 9 & RM257-RM553 & 5.22 & 9.61 & -1.32 & & & \\
\hline \multirow[t]{2}{*}{ PBN } & $q P B N 4$ & 4 & RM3367-RM1018 & 3.17 & 5.87 & 0.47 & & & \\
\hline & $q P B N 6^{a}$ & 6 & RM3138-RM3343 & 4.88 & 9.17 & -0.74 & 3.78 & 7.55 & -0.56 \\
\hline SNP & $q S N P 2$ & 2 & RM5699-RM424 & 3.20 & 7.46 & -9.80 & 3.67 & 9.51 & -8.13 \\
\hline \multirow[t]{3}{*}{ GNP } & $q G N P 4$ & 4 & RM241-RM470 & 2.72 & 5.01 & 9.05 & & & \\
\hline & $q G N P 8$ & 8 & RM506-RM152 & 3.06 & 5.96 & -9.85 & 4.12 & 7.23 & -11.53 \\
\hline & $q G N P 9$ & 9 & RM257-RM553 & & & & 5.66 & 8.98 & 10.32 \\
\hline \multirow[t]{9}{*}{ SD } & $q S D 2.1$ & 2 & RM279-RM1347 & 4.14 & 7.52 & -0.04 & & & \\
\hline & $q S D 2.2$ & 2 & RM5699-RM424 & & & & 4.19 & 6.91 & -0.04 \\
\hline & $q S D 2.3$ & 2 & RM475-RM1367 & 3.27 & 4.21 & -0.03 & & & \\
\hline & $q S D 3.1^{a}$ & 3 & RM1278-RM3766 & & & & 3.42 & 4.97 & 0.04 \\
\hline & $q S D 3.2$ & 3 & RM6080-RM6832 & 4.29 & 12.37 & -0.06 & 6.08 & 20.13 & -0.07 \\
\hline & $q S D 4$ & 4 & RM241-RM470 & 5.45 & 7.04 & 0.04 & & & \\
\hline & $q S D 6^{a}$ & 6 & RM3138-RM3343 & 5.20 & 7.56 & -0.04 & 2.97 & 4.89 & -0.04 \\
\hline & $q S D 7$ & 7 & RM455-RM505 & & & & 4.48 & 9.03 & -0.05 \\
\hline & $q S D 8$ & 8 & RM281-RM5545 & 6.29 & 7.77 & -0.04 & 3.16 & 4.53 & -0.03 \\
\hline \multirow[t]{2}{*}{$\mathrm{PN}$} & $q P N 1^{a}$ & 1 & RM5389-RM165 & 5.14 & 13.93 & 2.07 & & & \\
\hline & $q P N 2$ & 2 & RM1347-RM5699 & 6.16 & 14.48 & -2.03 & & & \\
\hline \multirow[t]{2}{*}{ SF } & $q S F 2$ & 2 & RM1347-RM5699 & & & & 2.69 & 6.71 & -2.53 \\
\hline & $q S F 3$ & 3 & RM6080-RM6832 & 6.55 & 24.89 & -5.02 & 6.21 & 17.84 & -4.15 \\
\hline \multirow[t]{3}{*}{ TGW } & $q T G W 2$ & 2 & RM1347-RM424 & 9.49 & 15.87 & 2.89 & 7.15 & 12.59 & 3.04 \\
\hline & $q T G W 3$ & 3 & RM6080-RM6832 & 21.37 & 44.35 & 5.66 & 21.63 & 47.05 & 5.09 \\
\hline & $q T G W 8$ & 8 & RM281-RM5545 & & & & 2.51 & 2.66 & 1.18 \\
\hline $\mathrm{GW}$ & $q G W 2$ & 2 & RM1347-RM5699 & 14.81 & 22.54 & 3.54 & 10.01 & 15.85 & 2.69 \\
\hline
\end{tabular}

$\mathrm{Chr}=$ chromosome; $R^{2}$ = proportion of phenotypic variation explained; Add = additive effect. ${ }^{a} \mathrm{QTLs}$ located near QTLs of PE.

Four QTLs for HD were detected on chromosomes 3, 6, and 7 (Table 3 and Figure 2). QHD3 and $q H D 6.1$ were located in the same marker intervals as the HD genes $H D 16$ and HD17, respectively (Matsubara et al., 2012; Hori et al., 2013). Three QTLs for PH were detected on chromosomes 1,6, and 12. QPH1 was located near the rice semi-dwarf gene, $s d-1$ (Spielmeyer et al., 2002). QTLs of panicle characteristics were detected for PL on chromosomes 1, 3, and 9, for PBN on chromosomes 4 and 6, for SNP on chromosome 4, for GNP on chromosomes 4 and 8, and for SD on chromosomes 2, 3, 4, 6, 7, and 8. QTLs were found on chromosomes 1 and 2 for PN, on chromosomes 2 and 3 for both SF and TGW, and on chromosome 2 for $\mathrm{GW}$. 

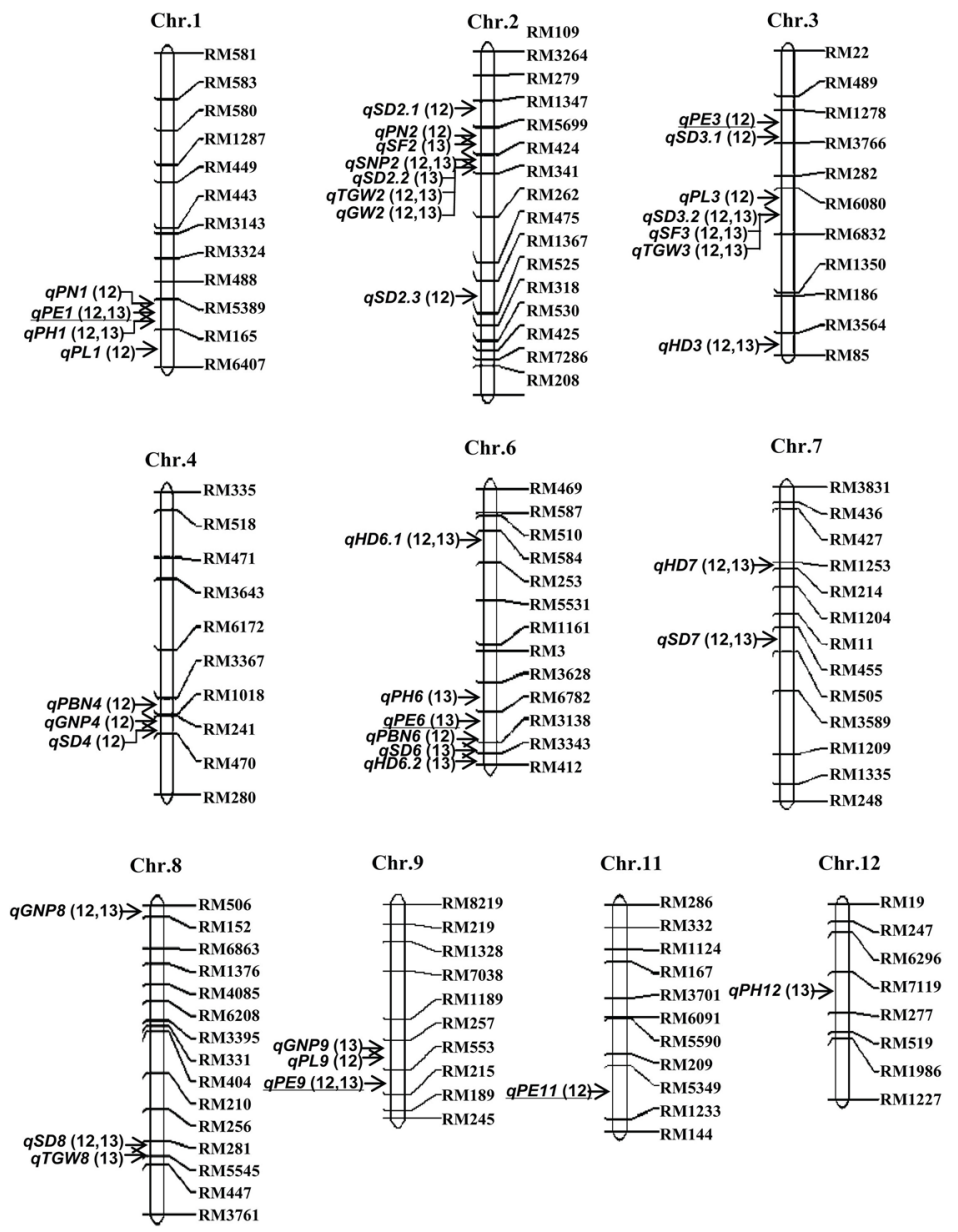

Figure 2. Quantitative trait locus (QTLs) for panicle exsertion and 11 yield-related traits in the RIL population detected in 2012 and 2013. The QTLs for panicle exsertion are underlined.

\section{DISCUSSION}

Significant correlations with PE have previously been reported for a number of agronomic traits (Yang et al., 2011; Hori et al., 2012). In the present study, significant relationships were observed between PE and yield-related traits (Table 2). There were significant positive correlations between PE and PH and PL, which have been confirmed in the multiple phenotypes of eui mutants, which have notably rapid elongation of plant height, excess PE, and an increased PE as compared with the wild type (Rutger and Carnahan, 1981; Luo et al., 2006). These positive correlations could be explained from the identification of mutants related to $\mathrm{PH}$. In these mutants, elongation of the culm, internode, and panicle were synergistically controlled by plant hormones such as GA, BRs, and ethylene in rice (Haubrick and Assmann 2006; Achard and Genschik, 2009; Hattori et al., 2009).

In the present study, PE was negatively correlated to PBN and SNP. The elongation 
of $\mathrm{PE}$ accompanies panicle development and is controlled by panicle differentiation signals during the reproductive phase (Wang et al., 2009). PBN originates from the reproductive apex and SNP is determined by cellular division of the panicle (Mu et al., 2005). In this case, the negative effects of PE on panicle branch and spikelet number could be explained in two ways. First, because longer PEs synergistically developed with longer and thinner panicles during panicle initiation, indicating that there is a competitive relationship between elongation and width of panicles. Second, because floret development and grain filling might decline due to the weak transportation of water and nutrients based on a longer PE. However, it is difficult to reach a definitive conclusion based only on the data obtained here. Unexpectedly, almost no correlation was found between PE and the yield component traits PN, SF, and TGW, which might be attributed to autogamous self-pollination and the independent genetic basis of the traits. However, some rice lines of PE that had negative values frequently presented lower spikelet fertility in this population, indicating that grain filling is influenced by sheathed panicles. The negative relationship between PE and GW may suggest that lower grain yield is directly derived from the scarcity of SNP companied by a longer PE.

Previous studies have found several QTLs for highly correlated traits located on the same or on neighboring chromosomal intervals, possibly resulting from pleiotropism or multigenic effects (Marathi et al., 2012; Swamy et al., 2014). In the present study, four QTL clusters were located on four intervals: RM5389-RM6407, RM1347-RM341, RM6080RM6832, and RM3628-RM412 on chromosomes 1, 2, 3, and 6, respectively (Figure 2). QTL clusters on chromosomes 1 and 6 mainly contained QTLs for length traits and alleles with negative effects were all derived from the shorter parent 'TD70', suggesting that pleiotropism of one major QTL rather than tight linkage of different QTLs might be responsible. The QTL cluster on chromosome 1 encompassed $s d-1$, a major semi-dwarf gene that affects plant height (Spielmeyer et al., 2002), while the QTL cluster on chromosome 6 had a similar locus with the semi dwarf and high-tillering gene SDT (Jiao et al., 2010). These data indicate that the semi dwarf genes are probably the major QTLs responsible for the pleiotropic phenotypes. In comparison with previous reports (Hittalmani et al., 2002; Hori et al., 2012; Cai et al., 2015), QTLs for $\mathrm{PH}$ and yield-related traits were usually detected on these chromosomal regions. Another two QTL clusters on chromosomes 2 and 3 were collocated for several yield and yield-related traits including TGW and GW traits, and their alleles were all from 'TD70' and had enhancing effects. Thus, these loci are worthy for use when improving grain size and weight of 'Kasalath', and other rice varieties with small grain size, by marker-assisted selection and are also important in QTL pyramiding programs. The results of these pleiotropic QTLs are consistent with the corresponding traits reported in previous publications (Swamy et al., 2014).

A total of five QTLs for PE were detected across two years. Among them, $q P E 1$ and $q P E 6$ were co-located with PH and panicle characteristics in the QTL clusters on chromosomes 1 and 6, respectively. This means that $q P E 1$ and $q P E 6$ were controlled by the semi dwarf genes $s d-1$ and $S D T$, respectively. Additionally, three QTLs $q P E 3, q P E 9$, and $q P E 11$ for PE were not included in the QTL clusters, indicating their specific genetic basis of PE different from other agronomic traits. To identify the genomic regions influencing PE across different populations, the QTL positions in the present study were compared with earlier reports, and three QTLs ( $q P E 1, q P E 3$, and $q P E 6)$ were found to map to the same genomic regions (Hittalmani et al., 2002; Qiao et al., 2007, 2008). For example, Hittalmani et al. (2002) identified one genetic locus that controls PE on chromosome 1 in the IR64 x Azucena DH population, which had the same chromosomal region as $q P E 1$ in the present study. Qiao et 
al $(2007,2008)$ reported consistent loci of $q P E 3$ and $q P E 6$ using 94 backcrossed inbred lines developed from 'Nippobare' and 'Kasalath'. The consensus on QTL locations suggests that these QTLs were adopted for transfer in different genetic backgrounds. The remaining two QTLs ( $q P E 9$ and $q P E 11)$ are reported for the first time and $q P E 9$ was stably expressed in 2012 and 2013; however, no consistency was found with previous QTLs. One possible explanation is that the genetic control of $\mathrm{PE}$ differs between rice genotypes and mapping populations. Moreover, the $q P E 9$ and $q P E 11$ alleles with the genetic effects from 'Kasalath' for increasing PE, might rarely exist in the mapping population of this study. Hence, the QTL markers would be applied for the genetic and direct improvement of PE in the elite germplasm 'TD70'.

In the future, stable QTLs could be used as priority loci for fine mapping, candidate gene identification, and allele mining to discover novel, naturally occurring variations by constructing near-isogenic lines in the progeny test. The cloning and functional analysis of the quantitative genes $q S H 1, P L O G 1$, and $q S W 5$ illustrate the importance of QTL mapping of agronomic traits. More investigation is needed into rare QTLs to ensure their validity and accuracy. Notably, the QTLs for PE were identified in the present study with minor effect, explaining phenotypic variance ranging from 6.51 to $8.61 \%$ with a LOD value of $2.5-3.8$. This was due to the fact that the PE trait was governed by many genes of small effects, and these QTLs will help to improve PE in a small but cumulative manner.

Overall, this study begins to characterize the quantitative inheritance of PE and yieldrelated traits using an RIL population derived from excellent rice germplasms 'TD70' and 'Kasalath' rather than from mutant materials. Further studies are needed to confirm the genetic role of these, which are stably expressed across elite rice germplasms or varieties, to fully understand their valuable potential in marker-assisted rice breeding, and to uncover their controlling genes.

\section{Conflicts of interest}

The authors declare no conflict of interest.

\section{ACKNOWLEDGMENTS}

Research supported by grants from the National Natural Science Foundation of China (\#31200144), the Jiangsu Agriculture Science and Technology Innovation Fund (CX[11]4021), and the China Agriculture Research System (\#CARS-01-47).

\section{REFERENCES}

Achard P and Genschik P (2009). Releasing the brakes of plant growth: how GAs shutdown DELLA proteins. J. Exp. Bot. 60: 1085-1092. http://dx.doi.org/10.1093/jxb/ern301

Bian JM, He HH, Li CJ, Shi H, et al. (2013). Identification and validation of a new grain weight QTL in rice. Genet. Mol. Res. 12: 5623-5633. http://dx.doi.org/10.4238/2013.November.18.11

Cai J, Zhang M, Guo LB, Li XM, et al. (2015). QTLs for rice flag leaf traits in doubled haploid populations in different environments. Genet. Mol. Res. 14: 6786-6795. http://dx.doi.org/10.4238/2015.June.18.21

Churchill GA and Doerge RW (1994). Empirical threshold values for quantitative trait mapping. Genetics 138: 963-971.

Cui KH, Peng SB, Xing YZ, Yu SB, et al. (2003). Molecular dissection of the genetic relationships of source, sink and transport tissue with yield traits in rice. Theor. Appl. Genet. 106: 649-658.

da Cruz RP, Milach SCK and Federizzi LC (2008). Inheritance of panicle exsertion in rice. Sci. Agric. 65: 502-507.

Dong SL, Zhang YH, Zhang YD, Chen T, et al. (2012). Construction of molecular genetic linkage map based on a rice RIL population and detection of QTL for tiller angle. Jiangsu J. Agr. Sci. 28: 236-242. 
Hattori Y, Nagai K, Furukawa S, Song XJ, et al. (2009). The ethylene response factors SNORKEL1 and SNORKEL2 allow rice to adapt to deep water. Nature 460: 1026-1030. http://dx.doi.org/10.1038/nature08258

Haubrick LL and Assmann SM (2006). Brassinosteroids and plant function: some clues, more puzzles. Plant Cell Environ. 29: 446-457. http://dx.doi.org/10.1111/j.1365-3040.2005.01481.x

Hittalmani S, Shashidhar HE, Bagali P, Huang N, et al. (2002). Molecular mapping of quantitative trait loci for plant growth, yield and yield related traits across three diverse locations in a doubled haploid rice population. Euphytica 125: 207-214. http://dx.doi.org/10.1023/A:1015890125247

Hori K, Kataoka T, Miura K, Yamaguchi M, et al. (2012). Variation in heading date conceals quantitative trait loci for other traits of importance in breeding selection of rice. Breed. Sci. 62: 223-234. http://dx.doi.org/10.1270/jsbbs.62.223

Hori K, Ogiso-Tanaka E, Matsubara K, Yamanouchi U, et al. (2013). Hd16, a gene for casein kinase I, is involved in the control of rice flowering time by modulating the day-length response. Plant J. 76: 36-46.

Je BI, Piao HL, Park SJ, Park SH, et al. (2010). RAV-Like1 maintains brassinosteroid homeostasis via the coordinated activation of BRI1 and biosynthetic genes in rice. Plant Cell 22: 1777-1791. http://dx.doi.org/10.1105/tpc.109.069575

Jiao Y, Wang Y, Xue D, Wang J, et al. (2010). Regulation of OSSPL14 by OsmiR156 defines ideal plant architecture in rice. Nat. Genet. 42: 541-544. http://dx.doi.org/10.1038/ng.591

Kende H, Cho HT and Cho HT; van der Knaap E (1998). Deepwater rice: A model plant to study stem elongation. Plant Physiol. 118: 1105-1110. http://dx.doi.org/10.1104/pp.118.4.1105

Konishi S, Izawa T, Lin SY, Ebana K, et al. (2006). An SNP caused loss of seed shattering during rice domestication. Science 312: 1392-1396. http://dx.doi.org/10.1126/science.1126410

Li H, Ye G and Wang J (2007). A modified algorithm for the improvement of composite interval mapping. Genetics 175 : 361-374. http://dx.doi.org/10.1534/genetics.106.066811

Lincoln SE, Daly MJ and Lander E (1992). Constructing genetic maps with MAPMAKER/EXP 3.0, in: Whitehead Institute Technical Report, third ed., Whitehead Institute, Cambridge, MA, USA.

Liu GL, Mei HW, Yu XQ, Zou GH, et al. (2008). QTL analysis of panicle neck diameter, a trait highly correlated with panicle size, under well-water and drought conditions in rice (Oryza sativa L.). Plant Sci. 174: 71-77. http://dx.doi. org/10.1016/j.plantsci.2007.09.011

Liu X, Wang Y and Wang SW (2012). QTL analysis of percentage of grains with chalkiness in Japonica rice (Oryza sativa). Genet. Mol. Res. 11: 717-724. http://dx.doi.org/10.4238/2012.March.22.1

Luo A, Qian Q, Yin H, Liu X, et al. (2006). EUI1, encoding a putative cytochrome P450 monooxygenase, regulates internode elongation by modulating gibberellin responses in rice. Plant Cell Physiol. 47: 181-191. http://dx.doi. org $/ 10.1093 / \mathrm{pcp} / \mathrm{pci} 233$

Ma J, Zhou KD, Ma WB, Wang XD, et al. (2002). The characteristics of the tissues of the first internode and their relations to the grain-filling for the different panicle types of rice. Acta Agron. Sin. 28: 215-220.

Marathi B, Guleria S, Mohapatra T, Parsad R, et al. (2012). QTL analysis of novel genomic regions associated with yield and yield related traits in new plant type based recombinant inbred lines of rice (Oryza sativa L.). BMC Plant Biol. 12: 137-155. http://dx.doi.org/10.1186/1471-2229-12-137

Matsubara K, Ogiso-Tanaka E, Hori K, Ebana K, et al. (2012). Natural variation in Hd17, a homolog of Arabidopsis ELF3 that is involved in rice photoperiodic flowering. Plant Cell Physiol. 53: 709-716. http://dx.doi.org/10.1093/ $\mathrm{pcp} / \mathrm{pcs} 028$

McCouch SR, Cho YG, Yano M, Paul E, et al. (1997). Report on QTL nomenclature. Rice Genet. Newsl. 14: 11-13.

McCouch SR, Teytelman L, Xu Y, Lobos KB, et al. (2002). Development and mapping of 2240 new SSR markers for rice (Oryza sativa L.). DNA Res. 9: 199-207. http://dx.doi.org/10.1093/dnares/9.6.199

$\mathrm{Mu}$ C, Nemoto K, You Z and Yamagishi J (2005). Size and activity of shoot apical meristems as determinants of floret number in rice panicles. Plant Prod. Sci. 8: 51-59. http://dx.doi.org/10.1626/pps.8.51

Qiao BJ, Wang YY, Zhu XB and Hong DL (2007). [QTL analysis of the uppermost internode length in rice under different growing environments]. Yi Chuan 29: 1001-1007. http://dx.doi.org/10.1360/yc-007-1001

Qiao BJ, Zhu XB, Wang YY and Hong DL (2008). Mapping QTL for three panicle exsertion-related traits in rice (Oryza sativa L.) under different growing environments. Acta Agron. Sin. 34: 389-396. http://dx.doi.org/10.1016/S1875$\underline{2780(08) 60017-6}$

Rutger JN and Carnahan HL (1981). A fourth genetic element to facilitate hybrid cereal production-a recessive tall in rice. Crop Sci. 21: 373-376. http://dx.doi.org/10.2135/cropsci1981.0011183X002100030005x

Sasahara H, Fukuta Y and Fukuyama T (1999). Mapping of QTLs for vascular bundle system and spike morphology in rice. Breed. Sci. 49: 75-81. http://dx.doi.org/10.1270/jsbbs.49.75

Shen ZT, Yang CD and He ZH (1987). Studies on eliminating panicle enclosure in WA type MS line of rice Oryza sativa subsp. indica). Chin J. Rice Sci. 1: 95-99. 
Spielmeyer W, Ellis MH and Chandler PM (2002). Semidwarf ( $s d-1)$, "green revolution" rice, contains a defective gibberellin 20-oxidase gene. Proc. Natl. Acad. Sci. USA 99: 9043-9048. http://dx.doi.org/10.1073/pnas.132266399

Swamy BPM, Kaladhar K, Reddy GA, Viraktamath BC, et al. (2014). Mapping and introgression of QTL for yield and related traits in two backcross populations derived from Oryza sativa cv. Swarna and two accessions of O. nivara. J. Genet. 93: 643-654. http://dx.doi.org/10.1007/s12041-014-0420-x

Wang L, Yin H, Qian Q, Yang J, et al. (2009). NECK LEAF 1, a GATA type transcription factor, modulates organogenesis by regulating the expression of multiple regulatory genes during reproductive development in rice. Cell Res. 19: 598611. http://dx.doi.org/10.1038/cr.2009.36

Wang Y and Li J (2011). Branching in rice. Curr. Opin. Plant Biol. 14: 94-99. http://dx.doi.org/10.1016/j.pbi.2010.11.002

Weng J, Gu S, Wan X, Gao H, et al. (2008). Isolation and initial characterization of GW5, a major QTL associated with rice grain width and weight. Cell Res. 18: 1199-1209. http://dx.doi.org/10.1038/cr.2008.307

Yamamoto T, Taguchi-Shiobara F, Ukai Y, Sasaki T, et al. (2001). Mapping quantitative trait loci for days-to-heading, and culm, panicle and internode length in a $\mathrm{BC}_{1} \mathrm{~F}_{3}$ population using an elite rice variety, Koshihikari, as the recurrent parent. Breed. Sci. 51: 63-71. http://dx.doi.org/10.1270/jsbbs.51.63

Yang SL, Yang RC, Qu XP, Zhang QQ, et al. (2001). Genetic and microsatellite analysis of a new elongated uppermost internode gene eui2 of rice. Acta Bot. Sin. 43: 67-71.

Yang YL, Rao YC, Li GG, Huang LC, et al. (2011). Genetic analysis of culms traits in rice. Mol. Plant Breed. 9: 160-168.

Yin H, Gao P, Liu C, Yang J, et al. (2013). SUI-family genes encode phosphatidylserine synthases and regulate stem development in rice. Planta 237: 15-27. http://dx.doi.org/10.1007/s00425-012-1736-5

Zhang Y, Zhang Y, Dong S, Chen T, et al. (2013). Identification of QTL for rice grain traits based on an extra-large grain material. Chin J. Rice Sci. 27: 122-128.

Zhu L, Hu J, Zhu K, Fang Y, et al. (2011). Identification and characterization of SHORTENED UPPERMOST INTERNODE 1, a gene negatively regulating uppermost internode elongation in rice. Plant Mol. Biol. 77: 475-487. http://dx.doi.org/10.1007/s11103-011-9825-6

\section{Supplementary material}

S1 Figure. Frequency distribution of 11 agronomic traits in the RIL population in 2012. 